\begin{tabular}{|lll|}
\hline & TOTOBUANG & \\
\hline Volume 6 & Nomor 1, Juni 2018 & Halaman 33-45 \\
\hline
\end{tabular}

\title{
ANALISIS STILISTIKA SENO GUMIRA AJIDARMA DALAM CERPEN REMBULAN DALAM CAPUCINO: KAJIAN POSTMODERNISME JEAN FRANCOIS LYOTARD \\ (Seno Gumira Ajidarma's Literary Stylistics in "A Short Story Rembulan dalam Capucino": A Study of Jean Francois Lyotard Postmodernism)
}

\author{
Kahar Dwi Prihantono \\ Universitas Diponegoro \\ Jalan Prof Soedarto, S.H. Tembalang Semarang \\ Pos-el: akanghaar@gmail.com
}

(Diterima: 28 Mei 2018; Direvisi: 30 Mei 2018; Disetujui: 5 Juni 2018)

\begin{abstract}
The research analyzes literary stylistics of Seno Gumira Ajidarma's short story, "Rembulan dalam Capucino ",by taking advantages of Lyotard's postmodernismperspectives. By applying andescriptive method, the writer found postmodern storytelling stylistics involving at least seven postmodern styles, namely fragmentation, sublim language play, pastiche, parody, kitsch, camp, and schizophrenia. Fragmentation wasfound in the style of merging separate fragments of rembulan and creating its new meanings. Sublime language play was seen on SGA trials to change something impossible to be possible. Pastiche style was seen in the quotation of Pablo Neruda's poem which expressed it took a glance to love someone and it took a very long time to forget someone. Parodic style was seen inthe exchange of "moon" for "soto Betawi" in Italian restaurant. Camp appeared in the elimination of characters' names as in common short stories. Schizophrenia arose at SGA's story about a "moon"(rembulan) that could serve as a sign or symbol of shifted meaning between the marker and the mark. When the established meaning of the "moon"(rembulan) referred to the 'celestial bodies which surround the earth, shine at night by the reflection of the sun' and 'night beauty', SGA shifted its meaning as a burden of forgetting someone.
\end{abstract}

Keywords: literary stylistics, short story, Lyotard postmodernism, rembulan, capucino

\begin{abstract}
Abstrak
Penelitian ini menganalisis stilistika sastra Seno Gumira Ajidarma (SGA) dalam cerita pendek "Rembulan dalam Capucino” dari sudut pandang postmodern Lyotard. Dengan menggunakan metode deskriptif, penulis menemukan kepostmodernan gaya SGA yang melibatkan sekurang-kurangnya tujuh gaya postmodernisme, yakni fragmentasi, permainan bahasa yang sublim, pastiche, parodi, kitsch, camp, dan skizofrenia. Gaya fragmentasi terlihat pada gaya penggabungan sejumlah fragmen terpisah tentang rembulan sehingga menciptakan makna baru. Permainan bahasa yang sublim tampak pada permainan SGA mengubah sesuatu yang tidak mungkin menjadi mungkin. Gaya pastiche terlihat pada pengutipan puisi Pablo Neruda yang menceritakan singkatnya mencintai seseorang dan lamanya waktu yang dibutuhkan untuk melupakan seseorang. Gaya parodi terlihat pada penukaran rembulan dengan soto Betawi di restoran Italia. Gaya kitsch, Gaya camp muncul pada peniadaan nama-nama tokoh selayaknya cerpen kebanyakan. Gaya skizofrenia muncul pada pengisahan SGA mengenai rembulan yang dapat dijadikansebagai tanda atau simbol makna yangbergeser antara penanda danpetandanya. Ketika makna rembulan yang telah mapan mengacu pada 'benda langit yg mengitari bumi, bersinar pada malam hari karena pantulan sinar matahari' dan 'kecantikan malam', SGA menggeser maknanya sebagai sebuah beban melupakan seseorang.
\end{abstract}

Kata-kata kunci: stilistika sastra, cerpen, postmodern Lyotard, rembulan, capucino

\section{PENDAHULUAN}

Karya sastra terus berkembang dari zaman ke zaman. Perkembangan tersebut menjadikan kajian postmodernisme dalam karya sastra semakin menarik untuk dilakukan. Pemilihan cerpen "Rembulan dalam Capucino” (RdC) karya Seno Gumira Ajidarma (SGA) sebagai objek kajian dilatarbelakangi oleh uniknya gaya pengisahan SGA yang menjadikan cerpen ini 
menarik untuk dikaji melalui perspektif postmodernisme.

Cerpen "RdC" menceritakan seorang perempuan yang baru seminggu bercerai memasuki sebuah kafe dan memesan menu Rembulan dalam Cappuccino. Semenjak kafe itu berdiri sepuluh tahun lalu, baru kali ini ada yang memesan rembulan dalam cappuccino. Kafe itu memang menyediakannya dan minuman itu memang hanya bisa dipesan satu kali, karena rembulan memang hanya satu.Seminggu kemudian, seorang lelaki memasuki kafe yang sama, dan memesan minuman yang sama, "RdC". Pelayan menjawab minuman itu sudah tidak lagi ada dan seorang perempuan telah memesannya minggu lalu. Pelayan meyakinkan bahwa minuman telah dibeli dan tidakada lagi di dalam daftar menu, ia juga meyakinkan sudah tidak ada rembulan lagi dalam seminggu ini. Pelayan kemudian menceritakan bahwa perempuan tersebut tidak memakannya dan dia minta rembulan itu dibungkus setelah tidak menyentuhnya sama sekali, hanya memandanginya saja berjam-jam sambil mengusap air mata. Ketika si perempuan meminta rembulan itu dibungkus. Ketika dibungkus, rembulan sebesar bola pingpong yang semula terapung-apung di dalam cangkir itu berubah menjadi sebesar bola basket. Kepala dapur bereaksi dan meminta agar pencoretan "RdC" dari daftar menu ditunda. Ia mengatakan rembulan itu belum hilang dan ia berandai siapa tahu perempuan itu mengembalikannya.Lelaki itu berpesan kalau dia muncul lagi, ia juga mau rembulan itu.

Si perempuan berada di suatu tempat tanpa cahaya, kelam, begitu kelam, seperti ditenggelamkan malam. Ia teringat gambaran bagaimana ayahnya diambil dari rumahnya di tengah malam buta. Digelandang dan diarak sepanjang kota sebelum akhirnya disabet lehernya dengan celurit sehingga kepalanya menggelinding di jalanan dan darahnya menyembur ke atas seperti air mancur deras sekali sampai menciprati orang-orang yang mengarak ayahnya itu. Rembulan itu berada di punggungnya sekarang, terbungkus dan tersimpan dalam ranselnya. Ia ragu akan ia berikan kepada bekas suaminya atau dibuang saja rembulan itu ke sungai, seperti membuang suatu masalah agar pergi menjauh selamanya dan tidak pernah kembali? Dalam kegelapan tanpa rembulan, perempuan itu tidak bisa melihat senyuman maupun air matanya sendiri di permukaan sungai yang mengalir perlahan dan ia tak tahu apakah masih harus mengutip Pablo Neruda, Tonight I can write the saddest lines...Tiga minggu kemudian, si perempuan mengembalikan rembulan dan minta diganti soto Betawi.

Beberapa penelitian tentang cerpen SGA pernah dilakukan sebelumya. Beberapa di antaranya adalah penelitian yang dilakukan oleh Supena (2013) yang menyelidiki novel Kitab Omong Kosong karya SGA yang melihat repertoar strategistrategi pengedepanan sifat antologis postmodernisme. Pluralitasontologisme itu dikelompokkan kedalam beberapa kategori di antaranya,yaitu (1) dunia-dunia, (2) konstruksi, (3) kata-kata, dan (4) pendasaran. Persinggungan antara fiksipostmodernisme dengan fiksi fantasi melihat bahwa antara teks yang satudengan teks yang lain bisa saling melintas juga menjadi dasar bagi terjadinya persinggungan antara fiksipostmodenisme dan fiksi fantastik. Hal ini terjadi sebagaimana persinggungan antara fiksi postmodernis dan fiksi ilmiah, yang dominan pada kedua jenisfiksi tersebut adalah sifat ontologisnya. Selain itu, "Analisis Hegemoni pada cerpen Iblis Tidak Pernah Mati Karya Seno Gumira Ajidarma" juga pernah dilakukan oleh Nurhadi (2004) yang melihat formasi ideologi dalam masyarakat, dan hubungan historis Iblis Tidak Pernah Mati sebagai bagian dari negosiasi ideologi yang terjadi dalam masyarakat. Kemudian Swaratyagita (2005) pernah melakukan penelitianuntuk mengungkap bentuk hegemoni penguasa 
dalam novel Negeri Senja yang ditampilkan melalui simbol-simbol yang terdapat di dalam teks dengan menggunakan Semiologi Roland Barthes mengenai fashionsistem.

\section{LANDASAN TEORI}

Stilistika merupakan objek baik bagi ilmu linguistik maupun ilmu sastra. Perbedaanya stilistika linguistik terbatas pada penelitian gejala bahasa secara deskriptif, yang dalam perkembangan kemudian disebut sebagai majas, sedangkan stilistika sastra melangkah lebih jauh pada aspek-aspek yang melatarbelakangi sekaligus tujuan yang hendak dicapai, sebagai penelitian evaluatif. Menurut Wellek dan Warren (1990:227) untuk meneliti aspek-aspek stilistika karya seorang pengarang di samping memahami kaidahkaidah linguistiknya perlu juga menelusuri penggunaan bahasa pada zamannya, sebab pada dasarnya stilistika adalah perbedaan penggunaan karya sastra dengan penggunaan bahasa pada zaman tertentu.

Karya seni, termasuk sastra, yang bersifat imajinatif, personal, dan khas menjadi bagian dari struktur sosial. Oleh karena itu, sikap dan gaya merupakan representasi peranan-peranan sosial, baik sebagai manifestasi perilaku individual maupun komunitas tertentu (Ratna, 2007:251). Perubahan kultural direfleksikan melalui gaya bahasa, sedangkan gaya bahasa dipengaruhi oleh masyarakat.

Seluruh aspek kehidupan merupakan tanda, yang digunakan sebagai sistem komunikasi. Sebuah tanda akan bermakna jika digunakan dalam proses interaksi dan komunikasi. Bahasa merupakan salah satu sistem komunikasi terpenting sekaligus rumit dan kompleks. Karya seni, melalui mekanisme struktur sosial, mengubah struktur sosiokultural yang statis, stagnasi, dan beku, menjadi dinamis, bergerak, dan cair, yaitu melalui mode, cara, gaya, dan gaya bahasa (Ratna, 2007:252). Wellek dan Warren (1990:228) menegaskan bahwa stilistika sastra memiliki wilayah yang lebih kaya, baik dibandingkan dengan stilistikalinguistik maupun retorika.

Postmodern menurut Lyotard (dalam Faisal, R. 2010:396--414) merupakan suatu pemutusan hubungan total dengan budaya modern dan bukan sekadar koreksi atas berbagai pemikiran dan budaya modern. Postmodernisme diartikan sebagai ketidakpercayaan pada berbagai bentuk metanarasi, ketidakpercayaan pada klaim kebenaran ilmu pengetahuan objektifuniversal. Ketidakpercayaan pada klaim kebenaran objektif-universal itu didasarkan atas kesadaran akan adanya keterbatasan dan ketidakmampuan dalam melihat realitas dari perspektif dan primitiv tertentu. Penolakan terhadap metanarasi berarti berakhirnya penjelasan yang bersifat universal tentang tingkah laku dalam rasionalitas instrumental.

Postmodernisme menurut McHale (dalam Pujiharto, 2005:88--97) merupakan istilah yang tidak ada acuannya karena postmodernisme merupakan suatu konstruksi. Oleh sebab itu, terdapat beragam pengertian postmodernisme. Hal yang penting menurut McHale adalah bahwa konstruksi postmodernisme yang dibangun memiliki konsistensi dan koherensi internal, ruang lingkup yang tidak begitu luas dan tidak begitu sempit, dan produktif.

Endraswara (2013:167) mengutip pendapat Lyotarddalam bukunya The Postmodern Condition, postmodern telah menentang mitos-mitos modern, menghilangkan batas-batas antara seni dan kehidupan masa kini, antara elit yang hirarkhis dengan budaya populer, antara gabungan stilistik dengan percampuran kode, mengubah hal yang tak mungkin menjadi mungkin. Penulis meyakini "RdC" ini menarik dikajidengan menggunakan pisau postmodern Lyotard. Melalui cerpen ini Seno mencoba menentang mitos-mitos modern dan mengubah hal yangtak mungkin menjadi mungkin dengan menggunakan kata-kata yang digeserkan makna-maknanya bukan makna yang sebenarnya, seperti sifat perahu dan kupu-kupu yang sudah dipahami 
secara total telah difragmentasikan oleh Seno. Hal inilah yang diamati dan dianalisis dalam penelitian ini dengan masalah penelitian, bagaimanakah gaya penceritaan Seno Gumira Ajidarma dalam cerpen "RdC" ditinjau dari posmodernisme Lyotard? Selanjutnya, tujuan penelitian ini adalah mengungkap gaya penceritaan SGA dalam cerpen "RdC".

Ciri pertama stilistika postmodern Lyotard adalah fragmentasi. Dalam karyaseni organik, materi seni dipandang sebagai suatu keutuhan, sementara dalam karya seni garda depan, bahan seni dipisahkan dari totalitas hidup dan diisolasi. Fragmen garda depan estetik menantang orang untuk menjadikannya sebagai bagian integral realitas dan menghubungkannya dengan pengalaman mereka (Lyotard, 1984).

Stilistika postmodern memainkan permainan bahasa yang sublim. Sublim tidak hanya berhubungan dengan kepedihan, kekelaman, kesunyian, bahaya, kedalaman, kekosongan, tetapi juga kemegahan, kemahaluasan, ketakterhinggaan. Dibanding bahasa yang indah, sublim jauh lebih mampu membangkitkan emosi terkuat yang ada dalam diri seseorang yang melampaui semua pembatasan penilaian 'rasional' yang telah diatur. Stilistika postmodernisme melakukan yang sebaliknya: memandang sesuatu yang di anggap tidak benar oleh kebanyakan orang di angkat dan di dekonstruksi sehingga sesuatu yang dianggap tidak benar bisa menjadi sesuatu yang dimaklumi karena memandang sesuatu dari sudut pandang yang berbeda. Stilistika postmodern juga memandang sesuatu yang di anggap tidak benar oleh kebannyakan orang dan di dekonstruksi, sehingga sesuatu yang dianggap tidak benar bisa menjadi sesuatu yang dimaklumi karena memandang sesuatu dari sudut pandang yang berbeda (Lyotard, 1984).

Bagi Lyotard (Lyotard, 1984), permainan bahasa adalah ikatan sosial yang mempersatukan masyarakat, interaksi sosial terlihat terutama dalam pengertian pengambilan langkah dalam permainan, pengambilan peran tertentu, dan partisipasi dalam pelbagai macam permainan bahasa. Dalam pengertian tersebut, Lyotard melihat diri sebagai interaksi semua permainan bahasa yang diikuti.

Konsep permainan bahasa ini dilakukan dengan cara bahwa masing masing pernyataan dapat didefinisikan menurut aturan-aturan yang menentukan sifat dan nilai gunanya. Menurut Lyotard, permainan bahasa yang sublim telah membawa kita melampaui batas pemikiran di mana penilaian harus mengakui ketidakmemadaian sumber dayanya, atau ketiadaan kriteria yang disepakati bersama, untuk menghadapi kasus-kasus yang melampaui semua pembatasan penilaian 'rasional' yang telah diatur (Lyotard dalam Lubis, A.Y. 2014).

Gaya posmodern juga dapat kita temui dalam ranah sastra terlebih kita dapat memahami bahwa sastra adalah bagian dari seni. Dalam bukunya yang berjudul Hiperrealitas Kebudayaan: Semiotika, Estetika, Posmodernisme, Yasraf Amir Pilliang (1999:149) mengungkapkan pendapat Lyotard "paling tidak terdapat lima idiom yang cukup dominan mencirikan estetika posmodern, yaitu (1) pastiche, (2) parodi, (3) kitsch, (4) camp, dan (5) skizofrenia" (Lyotard dalam Pilliang, 1999:149). Kelima idiom yang diungkap oleh Lyotard (dalam Pilliang 1999) ini merupakan rangkuman dari berbagai ahli yang memiliki pandangan yang berbedabeda, satu diantaranya adalah Baldick. Piliang merangkum penjelasan para ahli sembari membubuhkan pendapatnya sendiri sehingga ia berhasil merumuskan kelima idiom tersebut sebagai ciri estetika postmodernisme. Ia menjelaskan "pastiche" sebagai pinjaman yang disusun dari elemenelemen yang dipinjam dari berbagai penulis lain, atau dari penulis tertentu di masa lalu (Lyotard dalam Pilliang, 1999:149). Karakteristik pastiche muncul ketika sebuah 
teks boleh jadi meniru atau mengimitasi karya sastra lain atau karya terdahulu.

Parodi merupakan komposisi dalam prosa yang di dalamnya kecenderungankecenderungan demikiran dan ungkapan karakteristik dalam diri seorang pengarang atau kelompok pengarang diimitasi sedemikian rupa untuk membuatnya tampak absurd, khususnya dengan melibatkan subjek-subjek lucu dan janggal, imitasi dari sebuah karya yang dibuat modelnya kurang lebih mendekati aslinya, tetapi disimpangkan arahnya sehingga menghasilkan efek-efek kelucuan (Lyotard dalam Pilliang, 1999:153).

Camp merupakan bentuk seni yang menekankan dekorasi, tekstur, permukaan sensual dan gaya dengan mengorbankan isi. Pada karya camp objek-objek alam, manusia, dan binatang seringkali digunakan, namun secara ekstrem dideformasikan, misalnya dengan dibuat lebih kurus, ramping, jangkung, gendut, besar, dan lebar (Lyotard dalam Pilliang, 1999:163). Camp diciptakan sebagai satu jawaban terhadap "kebosanan" dan sekaligus merupakan satu reaksi terhadap keangkukan kebudayaan tinggi yang telah memisahkan seni dari makna-makna sosial dan fungsi komunikasi sosial. Camp selalu melibatkan unsur duplikasi dan menggunakan manerisme, seperti bulu mata yang dilentikkan, senyum rahasia, jas yang berjumbai, yang mengundang penafsiran ganda (Lyotard dalam Pilliang, 1999:165). Skizofrenia pada awalnya merupakan sebuah istilah psikoanalisis, yang pada awalnya digunakan untuk menjelaskan fenomena psikis dalam diri manusia. Kini istilah tersebut digunakan secara metaforik untuk menjelaskan fenomena yang lebih luas, termasuk di antaranya fenomena bahasa, sosial-ekonomi, sosial-politik, dan estetika. Dalam kebudayaan dan seni, skizofrenia digunakan sebagai metafora untuk menggambarkan kesimpangsiuran penggunaan bahasa. Kekacauan pertandaan terdapat pada gambar, teks, objek, dan bahkan kalimat
(Lyotard dalam Pilliang, 1999: 167). Dalam karya seni, karya skizofrenik dapat dilihat dari keterputusan dialog di antara elemenelemen dalam karya, yaitu tidak berkaitannya elemen-elemen tersebut satu sama lain, sehingga makna karya tersebut sulit untuk ditafsirkan. Menurut Kamus Besar bahasa Indonesia, skizofrenia bermakna "penyakit jiwa yang ditandai oleh ketidakacuhan, halusinasi, waham untuk menghukum, dan merasa berkuasa, tetapi daya pikir tidak berkurang" (https://kbbi. kemdikbud. go. id/entri/skizofrenia). Ciri "ketidakacuhan" inilah yang menjadi karakteristik pendukung skizofrenia yang melepaskan hubungan antar unsur dalam sebuah karya. Skizofrenia inilah yang juga disebut sebagai pergeseran penanda dan petanda.

Masalah yang dirumuskan penulis dalam penelitian ini adalah bagaimanakah gaya penceritaan SGA dalam "RdC" diltinjau dari postmodernisme Lyotard. Penelitian ini bertujuan mengungkap gaya tersebut. Penulis berharap penelitian ini dapat memberikan kontribusi dalam kajian stilistika sastra khususnya dalam ranah kajian postmodernisme.

\section{METODE PENELITIAN}

Data yang digunakan dalam penelitian ini adalah data primer dan datasekunder. Data primer adalah cerpen "RdC" karya Seno Gumira Ajidarma (dalam Kompas edisi Minggu 31 Agustus 2003), sedangkan data sekunder berupa buku-buku dan penelitian ilmiah yang berhubungan dengan permasalahan. Secara keseluruhan, penelitian ini tergolong penelitian deskriptif dengan menggunakan metode kualitatif. Metode kualitatif adalah prosedur penelitian yang berdasarkan danmenghasilkan datadata deskriptif berupa data tertulis (Bogdan dan Taylor dalam Meleong, 1995:3). Menurut Nawawi (2007:66) data kualitatif ini adalah data yang hanya dapat diukursecara tidak langsung. Data ini hanyadapat diamati atau diselidiki dengan 
menggunakan teori yang sesuai dengan permasalahan.

Dalam analisis data, penelitian ini menggunakan kajian stilistika postmodernisme Cara kerjateori postmodern Lyotard ini dimulai dengan melakukan analisis mengamati fragmentasi, permainan bahasa sublim, penggunaan pastiche, parodi, kitsch, camp dan skizofrenia yang memungkinkan makna bergeser dari penanda ke petanda.

\section{PEMBAHASAN}

\section{Fragmentasi}

Lyotard

menjelaskanbagaimana postmodernisme mencabut suatu elemen dari totalitaskonteks kehidupan, mengisolasi, danmencabut dari fungsinya.Selanjutnya, postmodernis menggabung-gabungkan sejumlahfragmen yang saling terisolasi,sehingga menciptakan makna. Makna yang dihasilkan tidakberasal dari konteks awal fragmen-fragmen tersebut.

Pada awal cerita, SGA menampilkan fragmentasi kehidupan modern dengan munculnya atau maraknya restoran Italia atau kafe-kafe yang menyediakan makanan atau minuman yang tentu saja menawarkan nama-nama menu asing.

Seminggu setelah perceraiannya, perempuan itu memasuki sebuah kafe, dan memesan Rembulan dalam Cappuccino. Ia datang bersama senja, dan ia harus menunggu malam tiba untuk mendapatkan pesanannya. (Ajidarma, Seno G. 2003 Paragraf ke-1)

Cappuccino $^{1}$ dalam lautan berwarna coklat, datang langsung dari tercemplung cangkir, tenggelam sebentar, tapi lantas pingpong-tapi bukan bola pingpong, ini rembulan... (Ajidarma, Seno G. 2003 Paragraf ke-2)

Kehidupan perkotaan sebagai satu fragmen menceritakan kebiasaan orangorang kota berkunjung ke kafe dan memesan makanan atau minuman. SGA menandai fragmen ini dengan pengenalan minuman capucino. Bahkan, ia melengkapi narasinya dengan catatan kaki untuk menjelaskan jenis minuman ini.

Kopi tradisional Italia, biasanya untuk sarapan-kopi espresso yang dibubuhi susu panas dan buih, sering juga ditaburi cokelat, dalam seduhan air panas 80 derajat celsius, dihidangkan dengan cangkir. (Sumber: dari bungkus gula nonkalori Equal).

Selanjutnya, SGA membawa tokohtokoh tanpa nama dalam cerpen "RdC" untuk dapat ditafsirkan sebagai tokoh yang perannya tidak untuk menginterpretasi atau mencocokan kedalam dunia yang di dalamnya ternyata mereka sendiri hidup, tetapi justru untuk menunjukan eksistensi dari suatu pluralitas. Fragmen kedua ia perkenalkan sehingga tokoh perempuan seakan berada di dunia yang terombangambing antara dendam akan zaman kegelapan saat pembantaian G30S/PKI, seperti dalam kutipan berikut.

Dia berada di suatu tempat tanpa cahaya, kelam, begitu kelam, seperti ditenggelamkan malam, sehingga bintangbintang yang bertaburan tampak jelas, terlalu jelas, seperti peta dengan namanama kota. Perempuan itu belum lupa, apalah artinya nasib satu manusia di tengah semesta, nasib yang sebetulnya jamak pula dialami siapa pun jua di muka bumi yang sebesar merica.Namun, ia merasa bagaikan kiamat sudah tiba. Agak malu juga sebetulnya.

Banyak orang lain harus hidup dengan gambaran bagaimana ayahnya diambil dari rumahnya di tengah malam buta. Digelandang dan diarak sepanjang kota sebelum akhirnya disabet lehernya dengan celurit sehingga kepalanya menggelinding di jalanan dan darahnya menyembur ke atas seperti air mancur deras sekali sampai menciprati orang-orang yang mengaraknya itu. Tidak sedikit orang yang hidup dengan kutukan betapa ibunya telah menjadi setan jalang yang 
memotong-motong alat kelamin lelaki sambil menyanyi dan menari, dan karena itu berhak disiksa dan diperkosa, padahal semua itu merupakan kebohongan terbesar di muka bumi. Hidup ini bisa begitu buruk bagi orang baik-baik meskipuntidak mempunyaikesalahan samasekali. Tanpa pembelaan sama sekali. ${ }^{2}$ Tanpa pembelaan. Tanpa...

(Ajidarma, Seno G. 2003 paragraf 12)

SGA memperkuat fragmennya dengan menyertakan catatan kaki pada penghujung cerpen "RdC" sebagai berikut.

Tentang penyiksaan sesama manusia Indonesia, bisa dilacak dalam sejumlah dokumen, antara lain, Pipit Rochijat, "Am I PKI or Non PKI?" dalam Indonesia edisi 40 (Oktober 1985); A Latief, Pleidoi Kol. A. Latief: Soeharto Terlibat G $30 \mathrm{~S}$ (2000); Sulami, Perempuan-Kebenaran dan Penjara (1999); Sudjinah, Terempas Gelombang Pasang (2003), dan tentu saja Pramoedya Ananta Toer, Nyanyi Tunggal Seorang Bisu (1995).

Fragmentasi

postmodernisme menyebabkan karya sastra cenderung memiliki beberapa sudut pandang dari tokoh yang ada didalam cerita, terdapat istilah wacana dalam wacana. Sudut pandang si perempuan dan si pria tentang rembulan. Karakteristik tersebut ditemukan dalam cerpen "RdC" yang berbeda dengan alur prosa modern. Di dalam cerpen ini setidaknyaditemukan mitos-mitos yang cobadiangkat dan dipercaya oleh banyakorang.

\section{Permainan Bahasa dan Yang Sublim}

Konsep "bahasa yang sublim" menurut Lyotard (1984) adalah bahasa yang melampaui semua kekuatan representasi kita, pengalaman yang tidak dapat dinyatakan dengan mode pemahaman konseptual atau indrawi secara memadai, dan yang berbeda dengan yang indah sejauh tidak menghasilkan keseimbangan atau kesesuaian yang harmonis antara kedua kemampuan tersebut. Selain itu yangsublim merupakan sarana menyatakan(dengan analogi) apa yang sama sekalitidak dapat diungkapkan. SGA di dalam cerpen "RdC" ini menyertakan banyak hal yangdapat dikategorikan yang sublim. Konsep permainan bahasa iniditemukan dalam cerpen, dimulai darikonsep "rembulan". Rembulan selama ini bermakna "benda langit yang mengitari bumi, bersinar pada malam hari karena pantulan sinar matahari' telah dimainkan oleh SGA sebagai bagian dari menu minuman yang terapung dalam minuman capucino. Rembulan tersebut "menghilang" dari langit segera setelah dipesan oleh si perempuan, seperti dalam kutipan paragraf ke-4, ke-5, dan ke-6 berikut.

"Rembulan dalam Cappuccino, satu!" Teriak pelayan ke dapur, dan kepala bagian dapur memijit-mijit nomor hp, seolah-olah ada persiapan khusus.

"Akhirnya tiba juga pesanan ini," katanya, "aku sudah bosan melihatnya di daftar menu tanpa pernah ada yang pesan."

Kepala dapur itu bicara dengan entah siapa melalui hp.

"Iyalah, turunin aja, sudah tidak ada lagi yang membutuhkan rembulan."

(Ajidarma, Seno G. 2003 paragraf 4)

Perempuan itu bukan tidak tahu kalau orang-orang memperhatikannya. Apakah perempuan itu akan memakan rembulan itu, menyendoknya sedikit demi sedikit seperti menyendok es krim, ataukah akan menelannya begitu saja seperti Dewa Waktu menelan matahari? (Ajidarma, Seno G. 2003 paragraf 5)

Ia memperhatikan rembulan yang terapung-apung di cangkirnya, permukaan cappuccino masih dipenuhi busa putih, seperti pemandangan Kutub Utara-tapi cappuccino itu panas, bagaikan masih mendidih. Ia senang dengan penampakan itu, dingin tapi panas, panas tapi dingin, segala sesuatu tidak selalu seperti 
tampaknya. (Ajidarma, Seno G. 2003 paragraf 6)

Menu minuman "rembulan dalam capucino" yang hanya disediakan sekali telah dipesan oleh si perempuan. Rembulan tersebut dapat terapung-apung dalam secangkir capucino yang ia pesan. Dalam hal ini, permainan bahasa sublim SGA telah mengubah sesuatu yang tidak mungkin menjadi mungkin. Hal ini diperkuat oleh narasi SGA pada paragraf ke-7 dan ke-8 yang mengungkapkan kedatangan seorang pria (mantan suami si perempuan) yang memesan menu yang sama. Pelayan menjawab bahwa menu tersebut telah dipesan mantan istrinya minggu lalu dan ia meyakinkan si pria untuk melihat rembulan yang telah hilang dari langit.

Seminggu kemudian, seorang lelaki memasuki kafe itu, dan memesan minuman yang sama

...

"Apakah Tuan tidak memperhatikan, sudah tidak ada rembulan lagi dalam seminggu ini?"

Lelaki itu tersentak.

"Seorang perempuan? Istri saya? Eh, maaf, bekas istri saya?"

Para pelayan saling berpandangan. Salah seorang pelayan menjelaskan ciri-ciri perempuan yang telah memesan Rembulan dalam Cappuccino itu.

"Ah, pasti dia! Dasar! Apa sih yang tidak ingin ditelannya dari dunia ini? Apakah dia makan rembulan itu?"

Para pelayan saling berpandangan lagi.

(Ajidarma, Seno G. 2003 paragraf ke-7)

Kemudian dia meminta rembulan itu dibungkus. Ketika dibungkus, rembulan sebesar bola pingpong yang semula terapung-apung di dalam cangkir itu berubah menjadi sebesar bola basket.

(Ajidarma, Seno G. 2003 paragraf ke-7)

SGA telah menjadikan sesuatu yang tidak mungkin menjadi mungkin dengan mengungkap beberapa hal. Pertama, restoran Italia memasang menu satu kali saja dan setelah dipesan menu akan dihapus. Kedua, rembulan dapat disajikan terapung di permukaan minuman capucino di dalam cangkir. Ketiga, rembulan di langit menghilang dan berpindah di atas capucino. Keempat, minuman "rembulan dalam capucino" dapat dibungkus untuk dibawa pulang si perempuan. Keenam, rembulan sebesar bola pingpong yang semula terapung-apung di dalam cangkir itu berubah menjadi sebesar bola basket.

Permainan bahasa yangsublim, yang memperlihatkan petunjukadanya heterogenitas radikal dalamwacana kebenaran dan nilai. Permainanbahasa yang sublim ini telah membawakita melampaui batas pemikiran dimana penilaian harus mengakuiketidakmemadainya sumber daya, atauketiadaan kriteria yang disepakatibersama, untuk menghadapi kasus-kasus yang melampaui semuapembatasan penilaian 'rasional' (Lyotard, Jean Francois. 1984 hlm 82). Permainan bahasa ini berlanjut ketika rembulan dapat menempel di punggung si perempuan dan terus menghilang dari langit malam sehingga malam terus gelap tanpa kehadiran rembulan, seperti pada kutipan paragraf ke-14 berikut.

Rembulan itu berada di punggungnya sekarang, terbungkus dan tersimpan dalam ransel-apakah ia berikan saja kepada bekas suaminya, yang diketahuinya selalu bercita-cita memesan Rembulan dalam Cappuccino? Kalau mau kan banyak cappuccino instant di lemari dapur (ia lebih tahu tempat itu daripada suaminya) dan meski rembulan di punggungnya sekarang sebesar bola basket, nanti kalau mau dimasukkan cangkir akan menyesuaikan diri menjadi sebesar bola pingpong. ... (Op Cit Ajidarma. 2003 paragraf ke-14)

\section{Pastiche}


Gejala atau kecenderungan posmodern lain juga dapat kita temui dalam cerpen "RdC". Ia menjelaskan "pastiche" sebagai pinjaman yang disusun dari elemen-elemen yang dipinjam dari berbagai penulis lain, atau dari penulis tertentu di masa lalu (Lyotard, Jean Francois. 1984:149). Karakteristik pastiche muncul ketika sebuah teks boleh jadi meniru atau mengimitasi karya sastra lain atau karya terdahulu. Pastiche didefinisikan sebagai karya sastra yang disusun dari elemen-elemen yang dipinjam dari berbagai penulis lain, atau penis lain di masa lalu. Fenomena pasticheditemukan dalam paragraf ke-4 "RdC".

Dalam kegelapan tanpa rembulan, perempuan itu tidak bisa melihat senyuman maupun air matanya sendiri di permukaan sungai yang mengalir perlahan- dan ia tak tahu apakah masih harus mengutip Pablo Neruda.

Tonight I can write the saddest lines...

(Ajidarma, Seno G. 2003 paragraf ke-14)

Elemen yang dipinjam SGA dari Pablo Neruda berfungsi sebagai pembangun suasana hati si perempuan. Dia dan bekas suaminya sama-sama tahu betul mengenai rembulan itu, ia bahkan sempat berpikir untuk membuang rembulan itu ke sungai, seperti membuang suatu masalah agar pergi menjauh selamanya dan tidak pernah kembali. Ia kemudian merasa bahwa ia yang mewajibkan dirinya berduka, karena selayaknyalah seorang istri yang diceraikan dengan semena-mena merasa terbuang, padahal perpisahan itu membuat peluangnya untuk bahagia terbuka luas.

Tonight I can write the saddest lines.

Pablo Neruda.

Write, for example,'The night is shattered and the blue stars shiver in the distance.'

The night wind revolves in the sky and sings.

Tonight I can write the saddest lines.
Tonight I can write the saddest lines.

To think that I do not have her. To feel that I have lost her.

To hear the immense night, still more immense without her.

And the verse falls to the soul like dew to the pasture.

What does it matter that my love could not keep her.

The night is shattered and she is not with me.

This is all. In the distance someone is singing. In the distance.

My soul is not satisfied that it has lost her.

My sight searches for her as though to go to her.

My heart looks for her, and she is not with me.

The same night whitening the same trees.

$\mathrm{We}$, of that time, are no longer the same.

I no longer love her, that's certain, but how I loved her.

My voice tried to find the wind to touch her hearing.

Another's. She will be another's. Like my kisses before.

Her voide. Her bright body. Her inifinite eyes.

I no longer love her, that's certain, but maybe I love her.

Love is so short, forgetting is so long.

Because through nights like this one I held her in my arms

my sould is not satisfied that it has lost her.

Though this be the last pain that she makes me suffer

and these the last verses that I write for her.

Pablo Neruda ini merupakan bagian dari gaya postmodernisme, yakni pastiche atau pinjaman dari karya lain. SGA juga menyertakan catatan kaki yang menerangkan puisi karya Pablo Neruda ini dalam paragraf kutipan atau paragraf ke-16. Puisi "Tonight I Can Write" ini bersumber pada puisi berbahasa Spanyol "Puedo Escribir" dalam 20 Puemas de amor y una Cancion desesperada (Twenty Love Poems and a 
Song of Despair) karya Pablo Neruda pada tahun 1924, terjemahan ke dalam bahasa Inggris oleh WS Merwin, terbit pertama kali tahun 1969.Puisi karya Pablo Neruda tersebut menceritakan kesedihan seseorang yang berpisah dengan pujaan hatinya. Perpisahan yang diakibatkan hilangnya rasa cinta dan keyakinan pujaan hati akan menjadi milik orang lain (I no longer love her, that's certain, but how I loved her. My voice tried to find the wind to touch her hearing. Another's. She will be another's). Puisi Pablo ini juga menegaskan bahwa mencintai seseorang sangatlah singkat tetapi melupakan seseorang adalah proses yang berkepanjangan, seperti beban rembulan yang dibawa oleh si perempuan. Adalah sebuah pilihan, apakah si perempuan terus akan bergundah gulana menggendong rembulan di punggungnya (beban) atau melepaskan diri dari kesedihan dan memilih untuk menggapai kebahagiaan yang luas terbentang di depannya dengan mengembalikan rembulan ke rumah makan Italia.

\section{Parodi}

Parodi merupakan komposisi dalam prosa atau puisi yang di dalamnya kecenderungankecenderungan pemikiran dan ungkapan karakteristik dalam diri seorang pengarang diimitasi sedemikian rupa untuk membuatnya tampak absurd, khususnya dengan melibatkan subjek-subjek lucu dan janggal, dan disimpangkan arahnya sehingga menghasilkan efek-efek kelucuan.

Tiga minggu kemudian, pada hari hujan yang pertama musim ini, perempuan itu muncul lagi di kafe tersebut.

"Saya kembalikan rembulan ini, bisa diganti soto Betawi?"

Itulah masalahnya.

"Tidak bisa Puan, kami tidak punya soto

Betawi, ini kan restoran Itali?

SGA menampilkan parodi di penghujung cerita. Si perempuan pada akhirnya memutuskan mengembalikan rembulan yang sudah ia beli ke rumah makan Italia. Ia meminta penukaran rembulan dengan soto betawi, sebuah parodi yang menarik di akhir cerita SGA.

\section{Camp}

Campmerupakan bentuk seni yang menekankan dekorasi, tekstur, permukaan sensual dan gaya dengan mengorbankan isi. Pada karya camp objek-objek alam, manusia, dan binatang seringkali digunakan, namun secara ekstrem dideformasikan, misalnya dengan dibuat lebih kurus, ramping, jangkung, gendut, besar, dan lebar (Pilliang, 1999: 163). Camp diciptakan sebagai satu jawaban terhadap "kebosanan" dan sekaligus merupakan satu reaksi terhadap keangkukan kebudayaan tinggi yang telah memisahkan seni dari maknamakna sosial dan fungsi komunikasi sosial. Camp selalu melibatkan unsur duplikasi dan menggunakan manerisme, seperti bulu mata yang dilentikkan, senyum rahasia, jas yang berjumbai, yang mengundang penafsiran ganda.

Cerpen "RdC" menampilkan tokohtokoh tanpa nama. Dalam cerpen tersebut pengarang sengaja menggunakan gaya penceritaan yang baru di tengah konvensi prosa yang telah ada. Bentuk semacam ini menunjukan kebebasan pengarangnya dalam mengekspresikan ide dan gagasannya yang tidak mau lagi dibatasi dengan adanya bentuk-bentuk atau konvensi, batasanbatasan atau aturan-aturan penulisan cerpen yang selama ini diikuti oleh pengarang cerpen yang lainnya. Tokoh perempuan, laki-laki, pelayan, kepala dapur, pun ayah si wanita tidak ada yang diberi nama. Gaya penceritaan SGA tersebut masuk dalam gaya posmodernisme yang berjenis camp.Camp adalah bentuk seni yang menekankan dekorasi, tekstur, permukaan sensual dan gaya dengan mengorbankan isi. Camp diciptakan sebagai satu jawaban terhadap kebosanan sekaligus merupakan satu reaksi terhadap keangkuhan kebudayaan tinggi yang telah memisahkan makna-makn sosial 
dan fungsi komunikasi sosial, seperti dalam kutipan-kutipan berikut.

Seminggu setelah perceraiannya, perempuan itu memasuki sebuah kafe, dan memesan Rembulan dalam Cappuccino. Ia datang bersama senja, dan ia harus menunggu malam tiba untuk mendapatkan pesanannya. (Ajidarma, Seno G. 2003 paragraf 1)

"Rembulan dalam Cappuccino, satu!" Teriak pelayan ke dapur, dan kepala bagian dapur memijit-mijit nomor $\mathrm{hp}$, seolah-olah ada persiapan khusus.

“Akhirnya tiba juga pesanan ini," katanya, "aku sudah bosan melihatnya di daftar menu tanpa pernah ada yang pesan."

Kepala dapur itu bicara dengan entah siapa melalui hp.

"Iyalah, turunin aja, sudah tidak ada lagi yang membutuhkan rembulan."

(Ajidarma, Seno G. 2003 paragraf 4)

Seminggu kemudian, seorang lelaki memasuki kafe itu, dan memesan minuman yang sama.

"Rembulan dalam Cappuccino," katanya.

Para pelayan saling berpandangan.

"Oh, minuman itu sudah tidak lagi ada

Tuan, seorang perempuan telah memesannya minggu lalu."

Lelaki itu terpana.

"Apakah Tuan tidak memperhatikan, sudah tidak ada rembulan lagi dalam seminggu ini?"

Lelaki itu tersentak.

"Seorang perempuan? Istri saya? Eh, maaf, bekas istri saya?"

Para pelayan saling berpandangan. Salah seorang pelayan menjelaskan ciri-ciri perempuan yang telah memesan Rembulan dalam Cappuccino itu.

"Ah, pasti dia! Dasar! Apa sih yang tidak ingin ditelannya dari dunia ini? Apakah dia makan rembulan itu?"

Para pelayan saling berpandangan lagi.

"Tidak Tuan..."

"Jadi?"

"Kalau memang perempuan itu istri Tuan..."
"Bekas...."

"Maaf, bekas istri Tuan, mungkin Tuan masih bisa mendapatkan rembulan itu."

"Maksudmu?"

"Dia tidak memakannya Tuan, dia minta rembulan itu dibungkus."

"Dibungkus?"

"Ya Tuan, ia tidak menyentuhnya sama sekali, hanya memandanginya saja berjam-jam."

(Ajidarma, Seno G. 2003 paragraf 7)

Tokoh tanpa nama dalam sebuah prosa sangat jarang dijumpai. Seluruh tokoh dalam "RdC" tidak diberi nama oleh SGA menunjukkan gaya perlawanan terhadap "narasi besar" dalam prosa Indonesia.

\section{Skizofrenia}

SGA menggunakan skizofrenia digunakan sebagai metafora untuk menggambarkan kesimpangsiuran penggunaan bahasa. Kekacauan pertandaan atau pergeseran penanda dan petanda terdapat pada penggambaran rembulan dan capucino.

Cappuccino dalam lautan berwarna coklat, datang langsung dari tercemplung cangkir, tenggelam sebentar, tapi lantas pingpongtapi bukan bola pingpong, ini rembulan. Semua orang berada dalam kafe diamdiam melangkah keluar, menengok ke langit, ingin membuktikan dengan mata kepala sendiri bahwa terapung-apung cangkir perempuan sebenarnya, seperti telah pelajari semenjak di sekolah dasar, yakni yang tiada pernah mereka saksikan sisi gelapnya, dan rembulan itu memang sudah tidak ada. Paragraf ke-2)

Di dalam "RdC" SGA memutus dialog di antara elemen-elemen dalam cerita, yaitu tidak berkaitannya elemen-elemen tersebut satu sama lain, sehingga makna karya tersebut sulit untuk ditafsirkan. Ciri "ketidakacuhan" inilah yang menjadi karakteristik pendukung skizofrenia yang melepaskan hubungan antar unsur dalam sebuah karya. Skizofrenia inilah yang juga disebut sebagai pergeseran penanda dan 
petanda. Capucino adalah kopi tradisional Italia, biasanya untuk sarapan-kopi espresso yang dibubuhi susu panas dan buih, sering juga ditaburi cokelat, dalam seduhan air panas 80 derajat celsius, dihidangkan dengan cangkir. Rembulan adalah 'benda langit yg mengitari bumi, bersinar pada malam hari karena pantulan sinar matahari'. Oleh SGA, konsep penanda rembulan dancapucino yang terdapat dalam cerpenini bergeser dari makna referensinya.Hal ini dikarenakan rembulan dalam cerpen tersebut tidakseperti rembulan yang secara umum telahdiketahui sebagai salah satu bagian tata surya. Pun capucino dalam cerpen tersebut hanya sebagaisebuah entertainer yang memunculkanfenomena dan menghibur orang.

SGA menggeser makna rembulan menjadi sebuah beban yang terus menempel pada punggung si wanita dan menjadikan malam-malamnya benar-benar gelap setelah perceraian dengan suaminya. Dia sebenarnya tahu mengenai rembulan itu, ia bahkan sempat berpikir untuk membuang rembulan itu ke sungai, seperti membuang suatu masalah agar pergi menjauh selamanya dan tidak pernah kembali. Ia kemudian merasa bahwa ia yang mewajibkan dirinya berduka, karena selayaknyalah seorang istri yang diceraikan dengan semena-mena merasa terbuang, padahal perpisahan itu membuat peluangnya untuk bahagia terbuka luas.

sekarang ia berada di sebuah jembatan dan sedang berpikir, apakah akan dibuangnya saja rembulan itu ke sungai, seperti membuang suatu masalah agar pergi menjauh selamanya dan tidak pernah kembali? Setiap orang mempunyai peluang bernasib malang, kenapa dirinya harus menjadi perkecualian? Ia seperti sedang mencurigai dirinya sendiri, janganjangan ia hanya mewajibkan dirinya berduka, karena selayaknyalah seorang istri yang diceraikan dengan semena-mena merasa terbuang, padahal perpisahan itu membuat peluangnya untuk bahagia terbuka seluas semesta...(Op Cit Ajidarma. 2003. Paragraf ke-14)

Tiga minggu kemudian, pada hari hujan yang pertama musim ini, perempuan itu muncul lagi di kafe tersebut.

"Saya kembalikan rembulan ini, bisa diganti soto Betawi?"

(Op Cit Ajidarma. 2003. Paragraf ke-15)

Fenomena di atas mencerminkan kesimpangsiuran penggunaan bahasa. Lyotard memandang bahwa, di dalam bahasa tidak ada keutuhan, yang ada hanyalah pulau-pulau bahasa, yang masingmasing diatur oleh sebuah system aturan yang tak bisa diterjemah kan ke dalam sistem yang lain. Ketika makna rembulan yang telah mapan mengacu pada 'benda langit yg mengitari bumi, bersinar pd malam hari karena pantulan sinar matahari' dan 'kecantikan malam', SGA menggeser maknanya sebagai sebuah beban hidup. Secara tersirat, SGA mengusung anti kemapanan, tidak percaya lagi pada sesuatu yang telah menjadi pakem atau ketetapan bersama.

\section{PENUTUP}

Dari pembahasan di atas dapatdisimpulkan bahwa cerpen "RdC" karya SGA merupakan salahsatu cerpen yang bergaya posmodernisme Lyotard. Kepostmodernan cerpen initerletak pada gaya pengisahan SGA yang melibatkan sekurang-kurangnya tujuh stilistika postmodernisme, yakni fragmentasi, permainan bahasayang sublim, pastiche, parodi, kitsch, camp, dan skizofrenia.

Gaya fragmentasi terlihat pada gaya penggabungan sejumlahfragmen terpisah tentang rembulan sehingga menciptakan makna baru. Permainan bahasayang sublim tampak pada permainan SGA mengubah sesuatu yang tidak mungkin menjadi mungkin. Gaya pastiche terlihat pada pengutipan puisi Pablo Neruda yang menceritakan singkatnya mencintai seseorang dan lamanya waktu yang 
dibutuhkan untuk melupakan seseorang. Gaya parodi terlihat pada penukaran rembulan dengan soto Betawi di restoran Italia. Gaya camp muncul pada peniadaan nama-nama tokoh selayaknya cerpen kebanyakan. Gaya skizofrenia muncul pada pengisahan SGA mengenai rembulan yang dapat dijadikansebagai tanda atau simbol makna yangbergeser antara penanda danpetandanya. Ketika makna rembulan yang telah mapan mengacu pada 'benda langit yg mengitari bumi, bersinar pd malam hari krn pantulan sinar matahari' dan 'kecantikan malam', SGA menggeser maknanya sebagai sebuah beban melupakan seseorang.

\section{DAFTAR PUSTAKA}

Ajidarma, Seno G. 2003. "Rembulan dalam Capucino" cerpen Harian Kompas edisi Minggu 31 Agustus 2003 paragraf 1 s.d 16.

Faisal, R. 2010. Kajian Postmodernisme pada Cerpen "Maryamah Karpov" Karya Andrea Hirata. Jurnal Artikulasi, 7(1), 396-414.

Hariyanto. 2004. Fenomena Parolklan Televisi Indonesia. Dalam Jurnal Bahasa dan Seni, 32(1), 112-126.

Lubis, A.Y. 2014. Postmodernisme:Teori dan Metode. Jakarta:RajaGrafindo Persada.

Lyotard, Jean Francois. 1984. The Postmodern Condition: A Report On Knoeledge. Diterjemahkan dari bahasa
Perancis oleh Geoff Bennington dan Brian Massumi. Manchester: Manchester University Press

Meleong, L. J. 2002. MetodePenelitian Kualitatif. Bandung:Remaja Rosda Karya.

Nawawi, H. 2007. Metode Penelitian Bidang Sosial. Yogyakarta:Gadjah Mada University Press.

Nurhadi. 2004. "Analisis Hegemonipada Iblis Tidak Pernah Matikarya Seno Gumira Ajidarma”.Tesis. Yogyakarta: Program Studillmu Sastra Program Pascasarjana Universitas Gadjah Mada.

Piliang, Y. A. 2003. Hipersemiotika:Tafsir Cultural Studies atas "Matinya Makna”. Bandung:Jalasutra.

Pujiharto. 2005. Konstruksi Postmodern dalam Cerpen Larung". Litera, 4, 8897.

Ratna, N. K. 2010. Metode Penelitian Sastra. Yogyakara: Pustaka Pelajar.

Supena, A. 2013. "PuitikaPostmodernisme dalam Novel Kitab Omong Kosong" karyaSeno Gumira Ajidarma. Tesis.Yogyakarta: Program Studi IlmuSastra Program PascasarjanaUniversitas Gadjah Mada. Swaratyagita, G. 2005. "RomanNegeri Senja karya Seno Gumira Ajidarma: Dari Simbolisasi Hingga Hegemoni”.Tesis. Program Pascasarjana Universitas Airlangga. 